\title{
Role of the magnetospheric and ionospheric currents in the generation of the equatorial scintillations during geomagnetic storms
}

\author{
L. Z. Biktash \\ Institute of Terrestrial Magnetism, Ionosphere, and Radio Wave Propagation, Russian Academy of Sciences (IZMIRAN), \\ Troitsk, Moscow Region, 142190, Russia
}

Received: 7 October 2003 - Revised: 18 June 2004 - Accepted: 2 July 2004 - Published: 23 September 2004

Part of Special Issue "Equatorial and low latitude aeronomy"

\begin{abstract}
The equatorial ionosphere parameters, $K_{p}, D_{s t}$, $\mathrm{AU}$ and $\mathrm{AL}$ indices characterized contribution of different magnetospheric and ionospheric currents to the $\mathrm{H}$ component of geomagnetic field are examined to test the geomagnetic activity effect on the generation of ionospheric irregularities producing VLF scintillations. According to the results of the current statistical studies, one can predict near $70 \%$ of scintillations from Aarons' criteria using the $D_{s t}$ index, which mainly depicts the magnetospheric ring current field. To amplify Aarons' criteria or to propose new criteria for predicting scintillation characteristics is the question. In the present phase of the experimental investigations of electron density irregularities in the ionosphere new ways are opened up because observations in the interaction between the solar wind - magnetosphere - ionosphere during magnetic storms have progressed greatly. According to present view, the intensity of the electric fields and currents at the polar regions, as well as the magnetospheric ring current intensity, are strongly dependent on the variations of the interplanetary magnetic field. The magnetospheric ring current cannot directly penetrate the equatorial ionosphere and because of this difficulties emerge in explaining its relation to scintillation activity. On the other hand, the equatorial scintillations can be observed in the absence of the magnetospheric ring current. It is shown that in addition to Aarons' criteria for the prediction of the ionospheric scintillations, models can be used to explain the relationship between the equatorial ionospheric parameters, $h^{\prime} F, f o F 2$, and the equatorial geomagnetic variations with the polar ionosphere currents and the solar wind.
\end{abstract}

Key words. Ionosphere (Equatorial ionosphere; Ionosphere-magnetosphere interactions; Ionospheric irregularities; Modelling and forecasting)

Correspondence to: L. Z. Biktash

(lsizova@izmiran.rssi.ru)

\section{Introduction}

The equatorial ionosphere of the Earth produces serious problems in communication and navigation systems during different kinds of disturbances, much like the polar ionosphere. However, contrary to the polar caps, the equatorial ionosphere occupies a vastly larger region of the Earth's ionosphere and is located over a much more densely populated area. The equatorial ionosphere, being much larger than ionosphere over the polar cap is a convenient instrument for studying the complex problems of ionosphere physics and space weather. Because of its high conductivity, the equatorial ionosphere is very sensitive to variations in the electric field due to several effects including magnetospheric convection, ionospheric dynamo disturbance, and various kinds of wave disturbances. Because of this, the equatorial ionospheric irregularities often occur in the region confined between $\pm 20^{\circ}$ magnetic dip latitudes. The equatorial ionospheric irregularities manifest as a spread $F$ in ionograms, reversals of drift velocities, scintillation of radio transmissions through the ionosphere, etc. The rapid fluctuations of the phase and intensity of a radio signal that has passed through the Earth's ionosphere, typically on a satellite-toground propagation channel, is scintillation. Mechanisms of the equatorial scintillation are better understood than its morphology. For a review of the equatorial scintillation phenomena in light of developments in the theory and measurements of the $F$-region equatorial irregularities, refer to the paper of Basu et al. (1977). Prediction of the scintillation parameters for the local time, day of the year, solar epoch and the state of the geomagnetic field are very important for the radio communication. Such prediction can help to avoid blackouts and distortions in VLF communication due to ionospheric irregularities and can also help to advance the understanding of the nature of scintillations. The understanding of the variation of scintillation activity with solar epoch and seasons is well established by Koster (1972) and Aarons et al. (1980). The scintillation activity during 
geomagnetic storms and disturbances is less well understood. Many groups have investigated scintillation activity to find the empirical relationships in terms of different geomagnetic indices: $K_{p}, D_{s t}$, etc. defined by the magnetospheric and ionospheric currents. Not all workers agreed on which is the best index to use for predicting scintillations. This is perhaps not surprising because there are several separate factors which have influence on the choice. Koster (1972) found that scintillation is related to magnetic activity $\left(K_{p}\right)$ through some factor which occurs (or fails to occur) during magnetic storms. Its presence inhibits nighttime scintillation. This factor, whatever it is, is not always present during magnetic storms; at least, it is not always present with sufficient intensity to fully inhibit scintillation. Aarons and DasGupta (1984) have suggested that the occurrence of postmidnight scintillation is enhanced if the recovery phase of the storm starts at midnight down to the local time sector. They considered that one of the necessary conditions for generation of $F$-region irregularities in the nighttime equatorial ionosphere is $F$-layer lifting to a region where the effects of recombination become unimportant in the relation to the development of the Rayleigh-Taylor type of instability. Study of local time effects on scintillation activity during different phases of geomagnetic storms was continued by Dabas et al. (1989). The magnetic storms were divided into three categories according to the times when their recovery phases, based on $D_{s t}$-variations, started, namely A (06:0018:00 LT), B (18:00-00:00 LT) and C (00:00-06:00 LT). The authors showed that the category $\mathrm{C}$ storms are more favorable for generation of irregularities at the magnetic equator. They also noted that under similar circumstances ionosond data showed a postmidnight increase in $h^{\prime} F$ as well in spread $F$. Aarons (1991) noted that the difficulty with this analysis is that data from the Lunping station $\left(23.0^{\circ} \mathrm{N} ; 122^{\circ} \mathrm{E}\right)$ data were used. At Lunping $h^{\prime} F$ never reached the altitudes necessary to produce irregularities. Aarons (1991) analyzed the equatorial scintillation data during the magnetic storms based on $K_{p}$ and $D_{s t}$ indices and concluded that the ring current can play a leading role directly or indirectly in establishing the conditions for equatorial $F$-layer irregularity generation or inhibition. Aarons (1991) categorized $D_{s t}$ variations during magnetic storms on categories when maximum $D_{s t}$ occurs: 1) 10:00-16:00 LT, 2) 00:00-06:00 LT, 3) 18:0022:00 LT and found that the first category of storms had more suitable conditions for the inhibition of scintillation. Banola et al. (2001) also had verified that the local time of maximum intensity of ring current plays a role in establishing the conditions necessary for scintillation activity. They showed that the electrojet strength during the daytime has no perceptible effect on the nighttime scintillation activity and scintillation occurrence had a tendency to decrease with increaseing $K_{p}$ and $A p$ indices. Alternatively, Dabas et al. (2003) proposed the equatorial electrojet strength as a useful parameter for the prediction of the scintillation development. Thus, these studies show that scintillation at low latitudes can be either inhibited or triggered during storms, depending on the phase of the storm and its local time of occurrence.
Koster's (1972) question about the factor which is or is not always present during magnetic storms, with sufficient intensity to fully inhibit scintillation, is still an open question. This is perhaps not surprising because there are several separate factors which influence to the choice. This paper continues the investigations mentioned above and the study explores sources which can directly be related to the rise and fall of the $F$-layer and can have an influence on scintillation activity. We shall use the different geomagnetic indices, the ionospheric parameters, $B_{z}$ component of the IMF (Interplanetary Magnetic Field), to study scintillation activity at the diplatitudes and shall classify the geomagnetic storms according to that presented by Aarons' category (1991) as the commonly accepted criteria to explore scintillation occurrence.

\section{Data}

The $D_{s t}$ values, planetary magnetic activity indices $K_{p}$, auroral indices $\mathrm{AU}$ and $\mathrm{AL}, B_{z}$-component of the IMF, ionospheric $F$-layer height $h^{\prime} F$ and occurrence times of scintillation activity during individual storms are the sources of our study.

\section{Scintillation activity during the geomagnetic storms}

\subsection{Storm 1: 16-19 December 1971, (Category 1).}

Figure 1 shows $D_{s t}$ and $K_{p}$ plots in the two lower panels and the IMF $B_{z}$ and the ionospheric $F$-layer height $h^{\prime} F$ for Huancayo in the two upper panels. $D_{s t}$ reaches its maximum -163 nT at 21:00 UT (16:00 LT at Huancayo) on 17 December 1971 , i.e. during daytime on Huancayo. The scintillation patch durations over Huancayo from the MARISAT satellite are shown by the blocks along the local time axis of the $h^{\prime} F$ plot. According to Aarons (1991) this was a Category 1 storm. For a relatively large number of days this period represents MARISAT observations over Huancayo. Only on the night of 17-18 December was there no observed scintillation activity. We can see from Fig. 1 that during this night the $B_{z}$ IMF was strongly positive and a quiet recovery phase of the ring current without additional injections was observed on the $D_{s t}$ plot. The ionospheric height was lower at $300 \mathrm{~km}$ this night and $K_{p}$ was decreasing during the storm recovery phase. Thus, conditions for the generation of scintillation activity during the storm recovery phase were not satisfied at this sector of the equatorial ionosphere.

\subsection{Storm 2: 18-21 December 1980, (Category 1).}

In Fig. 2 the two upper panels show the $B_{z}$ IMF, AL and $D_{s t}$ indices. Ionosperic height variations $h^{\prime} F$ for Huancayo and the $K_{p}$ index are presented in the two lower panels. The scintillation patch durations over Huancayo are shown by the blocks along the time axis of the $h^{\prime} F$ figure. This was a strong geomagnetic storm with a peak of $D_{s t}=-240 \mathrm{nT}$ at 
16-19DEC 1971

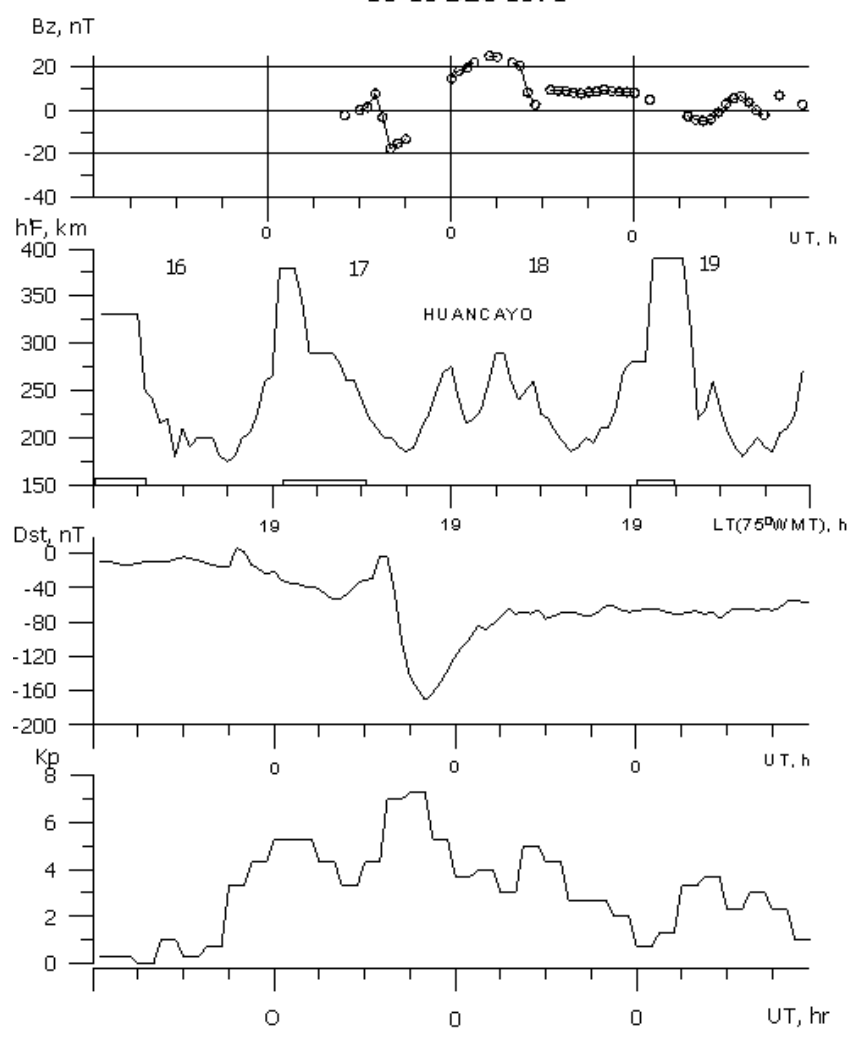

Fig. 1. Storm 1: 16-19 December 1971, Category 1 magnetic storm. $D_{s t}$ and $K_{p}$ plots are shown in the lower panels on the same time scale as the $B_{z}$ component of the IMF. The rectangular bars along the local time axis of the $h^{\prime} F$ plot at Huancayo indicate the duration of observed scintillations.

18:00 UT (13:00 LT at Huancayo) on 19 December 1980 when $K_{p}$ reached 8 . The ring current was generated by the negative of the IMF $B_{z}=-31 \mathrm{nT}$. The strong westward polar electrojet with $\mathrm{AL}=-1400 \mathrm{nT}$ was observed at the same time. The scintillations were observed every night except the night of 19-20 December 1980 when the $B_{z}$ of the IMF had positive values. The ionosperic heights $h^{\prime} F$ at Huancayo exceeded $350 \mathrm{~km}$ and $K_{p}$ increases were observed when scintillations occurred. Figure 2 shows that the absence of scintillations is associated with a $K_{p}$ decrease during the recovery phase of the magnetic storm. The ionospheric height $h^{\prime} F$ was less than $350 \mathrm{~km}$ and the westward polar electrojet $(\mathrm{AL}<200 \mathrm{nT})$ was very small this night. Because $\mathrm{AL}$ hourly index reflects the processes related to the westward polar electrojet and during the $B_{z}>0$ it was small we can say that the electric fields from the polar region didn't penetrate to the equatorial ionosphere. It should be noted that the auroral electrojet has a faster recovery phase than the ring current, as one can see from the $\mathrm{AL}$ and $D_{s t}$ plots. For example, on 19 December 1980 at 00:00 UT (19:00 LT for Huancayo), the strong ring current was still strong while AL had already reached its quiet level near $-200 \mathrm{nT}$.
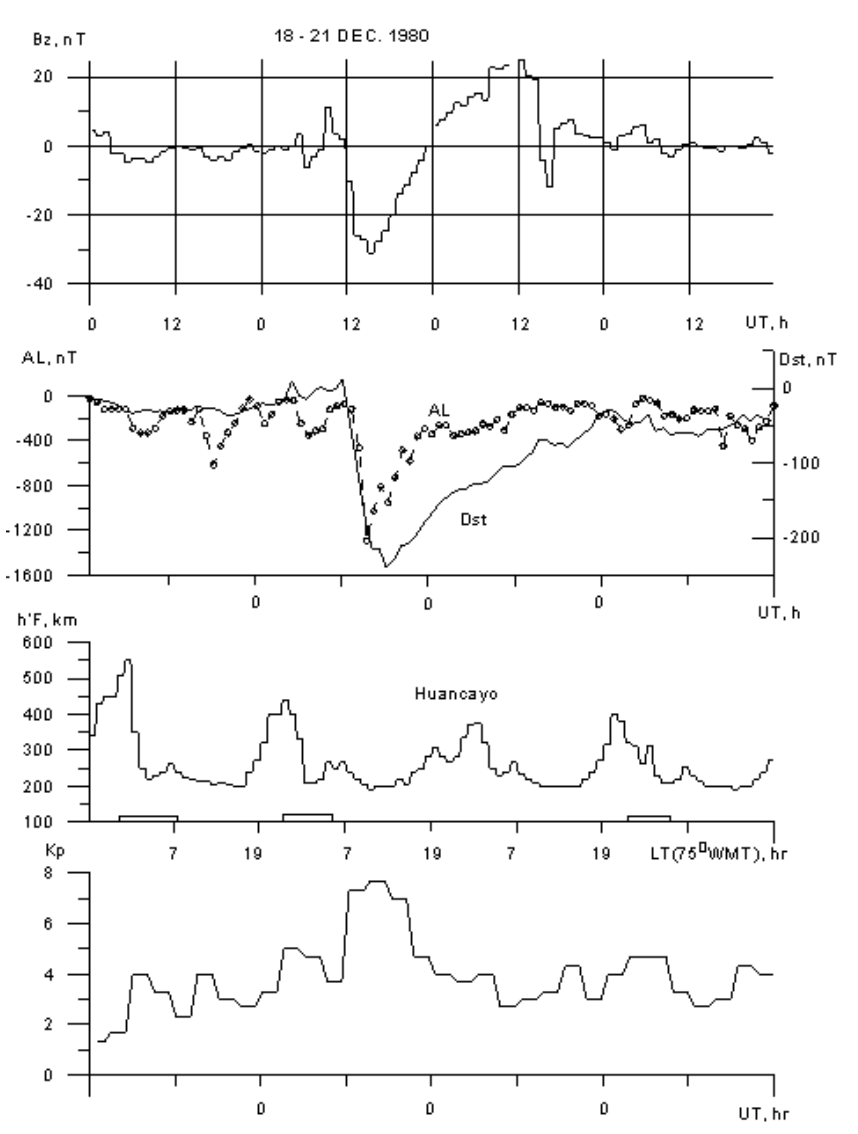

Fig. 2. Storm 2: 18-21 December 1980, Category 1 magnetic storm. The upper two panels show IMF $B_{z}, \mathrm{AL}$, and $D_{s t}$ on the same time scale as $K_{p}$. The rectangular bars along the local time axis of the $h^{\prime} F$ plot at Huancayo indicate the durations of observed scintillations.

\subsection{Storm 3: 4-9 March 1981, (Category 1).}

Figure 3 presents the IMF $B_{z}$ component, the ionospheric $F$ layer height $h^{\prime} F$ variations at Huancayo, $K_{p}$ and $D_{s t}$ indices. The scintillation patch durations are shown along the time axis of the $h^{\prime} F$ figure for Huancayo. The scintillation activity at 00:00 UT on 4 March 1981 was observed before the magnetic storm with $D_{s t}=-50 \mathrm{nT}$ and $K_{p}=4$, the IMF $B_{z}$ slightly negative, and $h^{\prime} F$ near $450 \mathrm{~km}$. The inhibition of irregularities and scintillations on the night of 5-6 March 1981 is associated with a preceding strongly positive IMF $B_{z}$ and $h^{\prime} F$ below $350 \mathrm{~km}$. Aarons (1991) associated this inhibition with the state of the $K_{p}$ and $D_{s t}$ indices. We added to this study the IMF $B_{z}$ component variations and virtual height variations $h^{\prime} F$ at Huancayo. The initial phase of the storm and the subsequent main phase decrease was generated by the positive solar wind electric field with negative $B_{z}$ IMF more than $-25 \mathrm{nT}$. The scintillations were observed over Huancayo just preceding the part of the main phase of this great magnetic storm on the morning of 5 March 1981 with $K_{p}=7$, $D_{s t}=-170 \mathrm{nT}$, and $h^{\prime} F$ decreasing from $500 \mathrm{~km}$. The maximum of $D_{s t}=-215 \mathrm{nT}$ was in the daytime at 11:00 LT for 


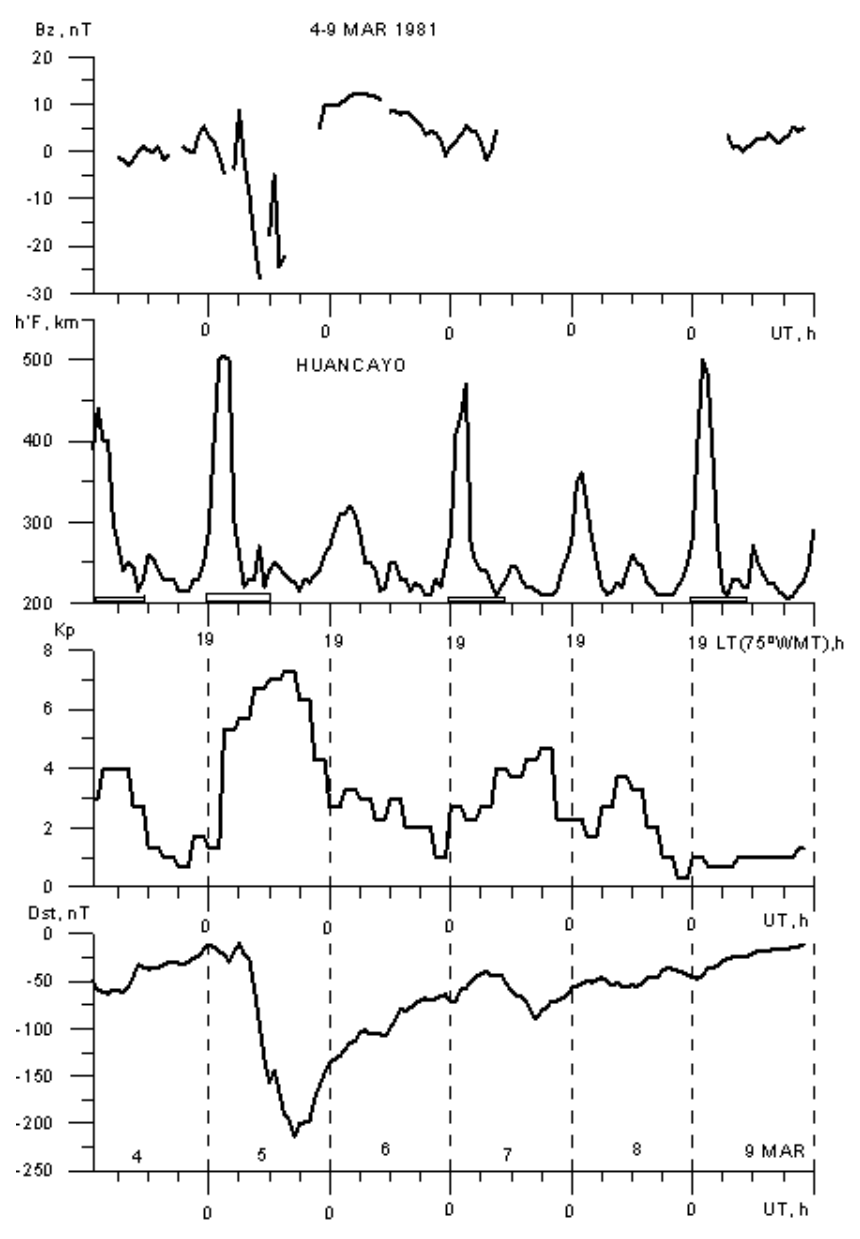

Fig. 3. Storm 3: 4-9 March 1981, (Category 1). The IMF $B_{z}$ component, the ionospheric $F$-layer height $h^{\prime} F$ at Huancayo, $K_{p}$ and $D_{s t}$ indices are presented. The scintillation patch durations for Huancayo are shown along the time axis of the $h^{\prime} F$ figure.

Huancayo. After 16:00 UT on 5 March the recovery phase began. The IMF $B_{z}$ was practically positive during 20 hours. This provided a quiet recovery for the ring current on 5-6 March 1981, during which time $K_{p}$ decreased and $h^{\prime} F$ at about $300 \mathrm{~km}$ didn't reach the height where irregularities are formed. Thus, small magnetospheric perturbations could not influence the equatorial ionosphere, and scintillations were not generated during the night of 5-6 March 1981. On the nights of 7-8 and 9-10 March 1981 the ionosphere height $h^{\prime} F$ reached $500 \mathrm{~km}$ after the southward turning of the IMF $B_{z}$ and scintillations were observed on these nights. During the night of 8-9 March 1981, $h^{\prime} F$ maximum was near $350 \mathrm{~km}$, and $K_{p}$ was decreasing. Unfortunately, we do not have the $B_{z}$ IMF for the ring current recovery period. However, the $D_{s t}$ index was available as shown during the quiet recovery phase of the ring current and $K_{p}$ reduced from 4 to 2 . This produced conditions that inhibited scintillations during this night.

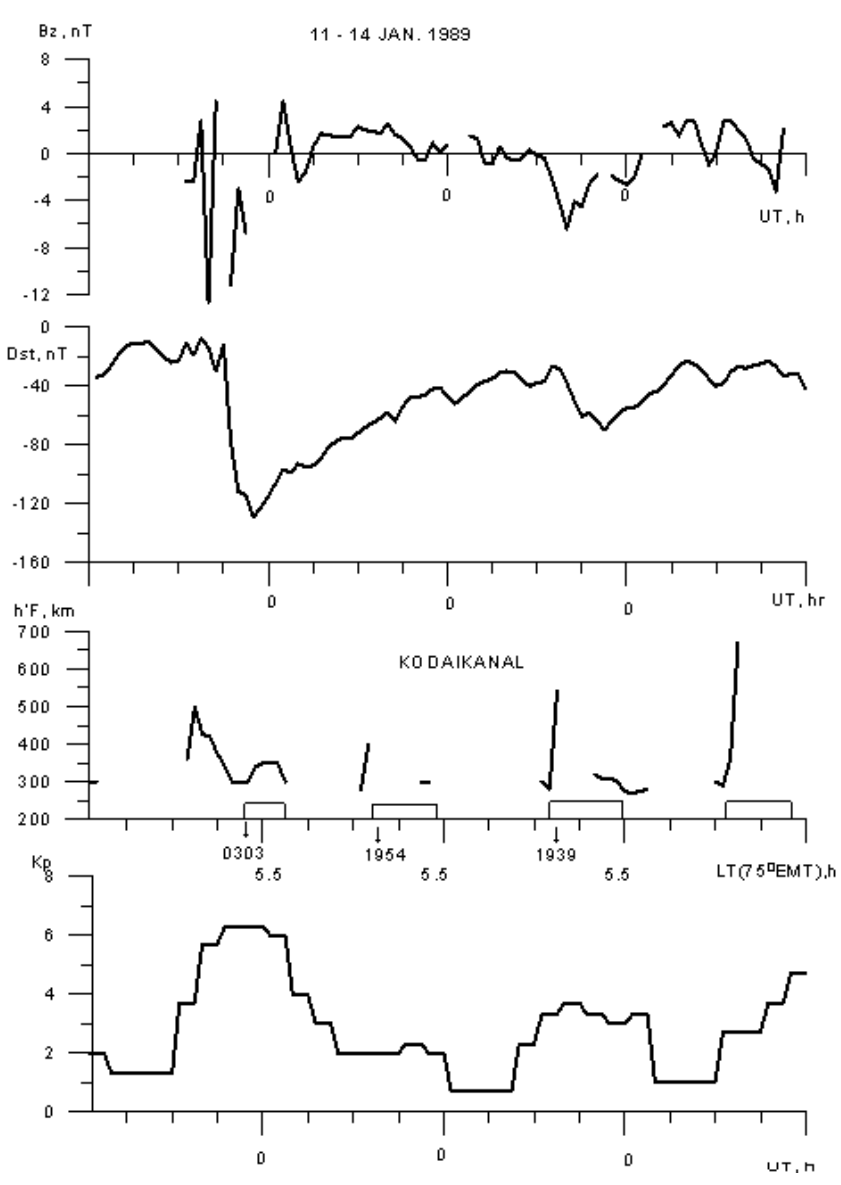

Fig. 4. Storm 4: 11-14 January 1989, (Category 2). The upper two panels show the IMF $B_{z}$ and $D_{s t}$ variations. The lower two panels show the ionospheric $F$-layer height $h^{\prime} F$ at Kodaikanal and the $K_{p}$ index. The times and durations of scintillation activity are marked by the rectangles along the time axis of the $h^{\prime} F$ plot.

\subsection{Storm 4: 11-14 January 1989, (Category 2).}

In Fig. 4 the upper two panels show the $B_{z}$ IMF and $D_{s t}$ variations. The lower two panels show the ionospheric $F$-layer height $h^{\prime} F$ at Kodaikanal and the $K_{p}$ index. The times of scintillation activity are marked by the blocks along the local time axis of the $h^{\prime} F$ plot. Banola et al. 2001 studied this magnetic storm. They showed that this magnetic storm followed Aarons' category 2. On the night of 11-14 January the post sunset steep height increase of $h^{\prime} F$ up to more than $500 \mathrm{~km}$, $400 \mathrm{~km}, 540 \mathrm{~km}$ and $670 \mathrm{~km}$, respectively, resulted in spread $F$ and hence strong scintillations on all of these days. These scintillations were associated with the southward $B_{z}$ IMF. The $B_{z}$ of IMF was slightly positive on 12 Jannuary 1989 between 06:00 and 18:00 UT during the magnetic storm recovery phase, but was not sufficiently positive to inhibit the scintillations as during storms 1 and 2 . The IMF $B_{z}$ turned southward before the scintillation activity this night. 


\subsection{Storm 5: 16-19 March 1989, (Category 3).}

Figure 5 presents a magnetic storm that is classified as Aarons' Category 3 for the Indian sector. The two upper panels show the IMF $B_{z}, \mathrm{AU}$ and $\mathrm{AL}$ variations. The two lower panels show $K_{p}$ and $D_{s t}$ indices. Occurence times of scintillation activity at Trivandrum are shown by the blocks along the time axis of the $D_{s t}$ plot. As seen from the figure, it was a moderate but very complex geomagnetic storm. Banola (2001) classified this storm as Category 1. The first minimum of $D_{s t}=-117 \mathrm{nT}$ was observed on 16 March at 13:00 UT or 18:30 LT, the second minimum of $D_{s t}=-119$ on 17 March at 11:00 UT or 16:30 LT in the Indian sector. We classify this storm as a Category 3 magnetic storm for the Indian sector. After 12:00 UT on 16 March 1989, during the recovery phase of the magnetic storm, the IMF $B_{z}=6 \mathrm{nT}$ was positive, with $K_{p}$ and $\mathrm{AU}$ decreasing the $\mathrm{AL}$ and $D_{s t}$ were increasing. Absence of scintillation activiy during the recovery phase of the magnetic storm on the nights of 16-17 and 17-18 March is associated with $K_{p}$ decreasing and AL increasing. The scintillations on 18-19 and 19-20 March were accompanied by the negative $B_{z} \mathrm{IMF}$, with $K_{p}$ increasing, $\mathrm{AL}$ and $D_{s t}$ decreasing. Thus, this geomagnetic storm was of Category 3, but for scintillations its behavior was similar to Category 1.

Thus, the events considered indicate that the IMF $B_{z}$ component, $D_{s t}, K_{p}$ and AL indices, and $h^{\prime} F$ can play a role in the generation of the nighttime scintillations. The equatorial ionospheric height $h^{\prime} F$ was increased when the IMF $B_{z}$ turned southward or was negative. The $D_{s t}, K_{p}, \mathrm{AU}, \mathrm{AL}$ indices showed increasing geomagnetic activity when conditions for generation of scintillations were formed at the equatorial ionosphere. The ring current decay began when the IMF $B_{z}$ component had positive values or turned northward. When $D_{s t}, K_{p}$ and the auroral indices showed decreasing of geomagnetic acitvity, $h^{\prime} F$ was low and the equatorial scintillations were not generated.

\section{Discussion}

The examples considered indicate that there can be different causes for generation or inhibition of the equatorial scintillations. Because the $K_{p}, D_{s t}, \mathrm{AU}, \mathrm{AL}$ indices are defined by the different magnetospheric and ionospheric currents one needs to decide which of these is the best indicator for predicting the equatorial scintillations. Comparing the VLF drift velocities and VHF scatter on the Jicamarca radar, the idea was suggested by Farley et al. (1970) of a threshold height above which the $F$-layer has to go before irregularities associated with spread $F$ can be generated. Basu et al. (1977) proposed that the observed scintillation activity at the equator and patches of activity off the equator may perhaps be due to varying thickness of the layers of irregularities in the transionospheric propagation of the signal. Rastogi and Woodman (1978), Rastogi and Aaarons (1980) and Rastogi et al. (1981) noted the fact that the occurrence of spread $F$ on
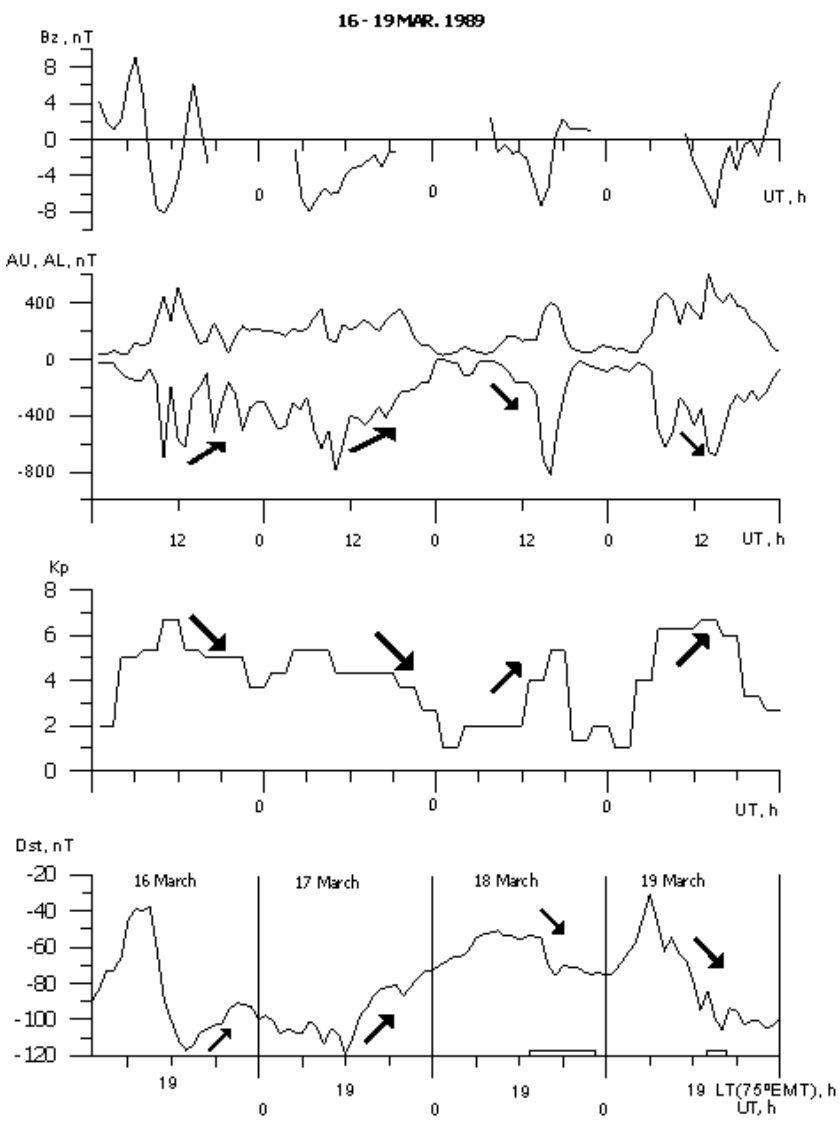

Fig. 5. Storm 5: 16-19 March 1989, (Category 3). The upper two panels show the IMF $B_{z}, \mathrm{AU}$ and $\mathrm{AL}$ variations. The lower two panels show the $K_{p}$ and $D_{s t}$ indices. The scintillation durations in the Indian sector are shown by the rectangles along the time axis of the $D_{s t}$ plot.

the ionograms in the evening hours is preceded by a rapid rise in the $F$-layer. This fact has led to the theory that there are irregularities in the upper $F$-region which appear on the ionograms only when the height of the $F$-region rises above the threshold level. It was found by Dabas et al. (1989), Aarons et al. $(1991,1997)$, as a general guide, that $D_{s t}$ variations are the best criteria to determine development of the equatorial irregularities. It also follows from these studies that the state of the ambient ring current and the equatorial ionosphere when the storm started are significant in the prediction of the equatorial scintillations. Numerous works present the experimental and theoretical relations found by their authors between the solar wind parameters and auroral ionosphere. The studies of Zmuda and Armstrong (1974), Iigima and Potemra (1978), Foster et al. (1989) and other authors lead to the conclusion that the field-aligned currents (FAC) constitute a major interconnection between the magnetosphere and polar ionosphere. Intensive ionospheric currents during geomagnetic storms and disturbances can change the quiet ionosphere parameters. Under these conditions the critical frequency $f o F 2$, virtual height $h^{\prime} F$, drift velocities and others ionospheric characteristics are mainly defined by the 


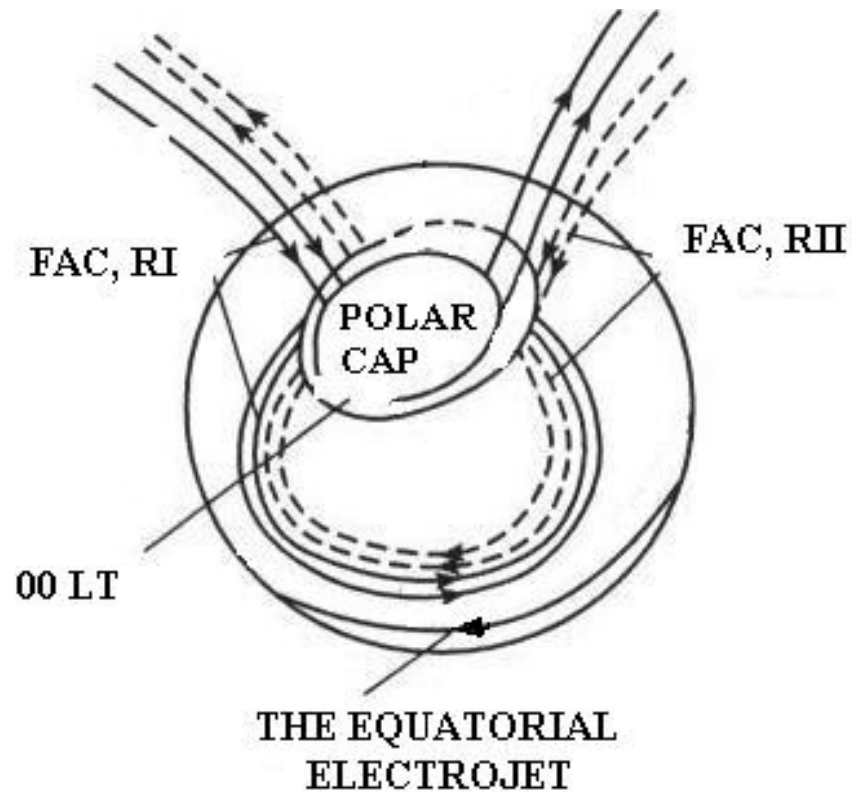

Fig. 6. The model of the field-aligned currents (FAC) of Regions 1 and 2 closing across the equatorial ionosphere.

state of the solar wind flowing around the Earth's magnetosphere. However, the equatorial ionosphere has been assumed to have a special advantage due to its being free from the FAC which occur in the polar ionosphere. As has been shown by Pudovkin et al. (1975), Rastogi and Patel (1975), Fejer et al. (1979), and Zakharov et al. (1989), the equatorial ionosphere is controlled by the magnetospheric and interplanetary magnetic fields. These authors presumed that the short-term equatorial ionospheric variations could be explained by the action of the auroral sources. However, a coupling mechanism between the auroral and equatorial ionosphere was not offered in these works. In succeeding years the equatorial ionosphere came to be regarded as highly subjected to the action of the auroral electric field and, in particular, from the field-aligned currents (FAC). The mechanism of the current system being formed at the equator by the field-aligned currents was proposed as far back in 1908 by Birkeland and has recently been further developed. With the advance in our knowledge about magnetosphere, the electrodynamics relation between the solar wind, magnetosphere and ionosphere are realized through the field-aligned currents. As was shown by Iigima and Potemra (1978), the field-aligned currents are closely connected with the auroral electrojets and the disturbance polar (DP) systems. They also showed that the location and intensity of the FAC are defined by the $B_{z}$ and $B_{y}$ components of the IMF. Zakharov et al. (1989), Denisenko and Zamai (1992), in theory, Kikuchi et al. (1996), Sizova (2002), using geomagnetic data, Sizova and Pudovkin (2000), using ionospheric data, had shown that the electric fields from the FAC could penetrate to the equatorial ionosphere and explain the equatorial electric field variations. In Fig. 6, the model of Sizova and Pudovkin (2000) of the field-aligned currents of the Region 1 and Region 2 closing across the equatorial ionosphere is presented. According to this model electric fields of the field-aligned currents penetrate through the midlatitudes to the low-latitude ionosphere and create the additional equatorial electric fields. These electric fields modify the equatorial electrojet and the ionospheric plasma vertical drift velocity. If the $B_{z}$ IMF is negative, the equatorial electrojet is enhanced by the Region $1 \mathrm{FAC}$ and plasma moves upward away from the $F$-layer. In this case a maximum of the $F 2$-layer is observed at the high altitudes where irregularities are observed. Therefore, the FAC are in continuous dynamics, thereby becoming responsible for the complicated nature of height variations at the equator. The examples presented in this study allow us to assume that the southward IMF $B_{z}$ by the electric field of the Region 1 FAC can form an additional eastward current system at the equatorial ionosphere. Under these conditions the virtual height $h^{\prime} F$ rises to high altitudes where scintillations can be generated. During the positive $B_{z}$ IMF the $F$-layer cannot rise up $350 \mathrm{~km}$ for the generation of scintillations. As shown by Burton et al. (1975), Sizova and Zaitseva (1984), Pudovkin at al. (1985) the magnetospheric ring current intensity is strongly dependent on the variations of the $B_{z}$ IMF. The magnetospheric ring current cannot directly penetrate to the equatorial ionosphere, though these are models with closed partial ring current through the polar ionosphere (Kikuchi et al., 1996). The equatorial electric field strengthening, on the other hand, can be observed in the absence of the ring current. As one can see from $\mathrm{AL}$ and $D_{s t}$ dynamics presented in Fig. 2, the auroral electrojet have a faster recovery phase than the ring current. The strong ring current on the 19-20 December 1980 night had no effects on the equatorial ionospheric height but the IMF $B_{z}$ did. As seen from Fig. 1, the same ring current intensity was observed on 18-19 December 1971 and 19-20 December 1971 but $h^{\prime} F$ variations were different on these nights. The $h^{\prime} F$ at Huancayo was near $300 \mathrm{~km}$ during positive IMF $B_{z}$ and reached $400 \mathrm{~km}$ altitude during negative $B_{z}$ IMF. These examples show that difficulties emerge when we consider the relation of the magnetospheric ring current to the equatorial ionosphere height variations and scintillation activity. Figure 5 shows that in practice, all categories can superimpose. For example, we have a $D_{s t}$ maximum at 10:00-16:00 LT at equatorial station (Category 1), but at 18:00-23:00 LT (Category 3) and at 00:00-06:00 LT (Category 2) new additional injections to the ring current associated with the large negative $B_{z}$ IMF may occur. In this case, we will have complex shapes of $D_{s t}$ variations and $D_{s t}$ category conception ceases to have its conventional meaning. The positive $B_{z} \mathrm{IMF}$ is likely to be the factor inhibited of the equatorial plasma motion to a height where scintillations can be generated.

\section{Conclusions}

The relationship between the equatorial ionospheric scintillations and the IMF $B_{z}, D_{s t}, K_{p} \mathrm{AU}, \mathrm{AL}$ indices has been demonstrated. It is shown that all of these indices are 
suitable for investigations of scintillaton activity at the equatorial ionosphere. Undoubtely, the $D_{s t}$ index is convenient and available one to study geomagnetic conditions during the ionospheric disturbances. However, the examples considered show that difficulties emerge when we consider the relation of the magnetospheric ring current to the equatorial ionosphere height variations and scintillation activity. The reason is that the $D_{s t}$ index does not include the auroral sources. For example, $K_{p}$ as the planetary (p) index carries information about auroral electrojets and we can see from our examples that scintillation activity decreases when $K_{p}$ reduces with positive $B_{z}$ IMF. This means that the auroral electrojets depicted by AU, AL-indices are connected with DP systems and the FAC moving polarward. The solar wind electric field through the FAC of Region 1 and Region 2 is likely to be the factor which generates or inhibites the equatorward penetration of the high-latitude electric field. If the equatorial ionospheric height is below or equal to $350 \mathrm{~km}$, then scintillations are not generated. The negative $B_{z}$ IMF enhances the auroral electric fields and the FAC electric fields can penetrate to equatorial ionosphere, and the ionospheric $F$-layer is raised above of threshold height $(\sim 350 \mathrm{~km})$. The equatorial irregularities associated with spread $F$ can be generated at this height and above, then scintillations can be observed there. Plasma falling from the high ionospheric altitudes is favoured for generation of the equatorial scintillations as well. The possible source of this phenomenon is the solar wind electric fields - the auroral and equatorial ionosphere coupling. The success of prediction of the ionospheric scintillations seems to use models which explain the relationship between equatorial ionospheric parameters such as $h^{\prime} F$, foF 2 and the equatorial geomagnetic variations with the polar ionosphere currents and the solar wind parameters such as $B_{z}$ IMF, $E_{y}$ - the solar wind electric field. Other processes, like tides, earthquakes, etc. can also change the ionospheric height and may play a role in the generation of the ionospheric scintillations. Taking into account the time delay between the $B_{z}$ IMF and the equatorial ionosphere phenomena, from the practical point of view, the relationships between the solar wind and the ionosphere parameters can be used for predicting scintillations. It should be noted that more detail investigations of these relationships with highprecision ionospheric and scintillation data are required.

Acknowledgements. The author would like to thank the referee for some very helpful suggestions.

Topical Editor M. Lester thanks D. R. Lakhsmi for her help in evaluating this paper.

\section{References}

Aarons, J., Mullen, J. P., Koster, J. P., da Silva, R. F., Madeiros, R. T., Bashby, A., Pantoja, J., Lanat, J., and Paulson, N. R.: Seasonal and geomagnetic control of equatorial scintillations in two longitudinal sectors, J. Atmos. Terr. Phys., 42, 861-866, 1980.

Aarons, J. and DasGupta A.: Equatorial scintillations during the major magnetic storm of April 1981, Radio Sci., 19, 731-739, 1984.
Aarons, J.: The role of the ring current in the generation or inhibition of equatorial $F$-layer irregularities during magnetic storms, Radio Sci., 26, 1131-1149, 1991.

Aarons, J., Mendillo, M., and Yantonsca, R.: GPS phase fluctuations in the equatorial region during sunspot minimum, Radio Sci., 32, 1535-1550, 1997.

Banola, S., Pathan, B. M., Rao, D. R. K.: Strength of the equatorial electrojet and geomagnetic activity control on VHF scintillations at the Indian longitudinal zone, Indian J. Radio Space Phys., 30, 163-171, 2001.

Banola, S.: Some characteristics of ionospheric irregularities at low latitudes deduced from VHF scintillation measurements, Doctor of philosophy thesis, Varanasi, India, 1-129, 2001.

Burton, R. K., McPherron, R. L., and Russel, C. T.: An empirical relationship between interplanetary conditions and $D_{s t}$, J. Geophys. Res., 80, 4204-4241, 1975.

Basu, S. and Kelley, M. C.: Review of equatorial scintillation phenomena in light of recent developments in the theory and measurement of equatorial irregularities., J. Atmos. Terr. Phys., 39, 1229-1242, 1977.

Dabas, R. S., Lakshmi, D. R., and Reddy, B. M.: Effect of geomagnetic disturbances on VHF nighttime scintillation activity at equatorial and low latitudes, Radio Sci., 4, 563-573, 1989.

Dabas, R. S., Singh, L., Lakshmi, D. R., Subramanyam, P., Chopra, P., and Garg S. C.: Evolution and dynamics of equatorial plasma bubbles: Relationships to ExB drift, postsunset total electron content enhancements, and equatorial electrojet strength, Radio Sci., 38, 1075-1087, 2003.

Denisenko, V. V. and Zamay, S. S.: Electric fields in the equatorial ionosphere, Planet. Space Sci., 40, 941-952, 1992.

Farley, D. T., Balsley, B. B., Woodman, R. F. and McClure, J. P.: Equatorial spread $F$ : Implications of VHF radio observations, J. Geophys. Res., 75, 7199, 1970.

Fejer, B. G., Gonzales C. A., Farley, D. T., and Kelley, M. C: Equatorial electric field during magnetically disturbed conditions, J. Geophys. Res., 84, 5797, 1979.

Foster J. C., Fuller-Rowell, T., and Evans, D. S.: Quantitative pattens of large-scale field-aligned currents in the auroral ionosphere, J. Geophys. Res., 94, 2555-2564, 1989.

Iigima, T. and Potemra, T. A.: Large-scale characteristics of the field-aligned currents associated with substorms, J. Geophys. Res., 83, 599-615, 1978.

Kikuchi, T., Luhr, H., Kitamura, T., Saka O., and Schlegel, K.: Direct penetration of the polar electric field to the equator during a DP event as detected by the auroral and equatorial magnetometer chains and the EISCAT radar, J. Geophys. Res., 101, 17 16117 173, 1996.

Koster, J. P.: Equatorial scintillation, Planet. Space Sci., 20, 19992014, 1972.

Rastogi, R. G. and Aarons, J.: Nighttime ionospheric scintillations and vertical drifts at the magnetic equator, J. Atmos. Terr. Phys., 42, 583-591, 1980.

Rastogi, R. G. and Aarons, J.: Nighttime ionospheric scintillations and vertical drifts at the magnetic equator, J. Atmos. Terr. Phys., 42, 593-597, 1980.

Pudovkin, M. I., Raspopov, O. M., and Kleimenova, N. G.: Disturbances in the Earth's electromagnetic field, Leningrad Univ. Press, Leningrad, 1, 154-156, 1975.

Pudovkin, M. I., Zaitseva, S. A., and Sizova, L. Z.: Growth rate and decay of magnetospheric ring current, Planet. Space Sci., 33, 1097-1102, 1985. 
Rastogi, G. and Patel, V. L.: Effect of interplanetary magnetic field on the ionosphere over the magnetic equator, Proc. Indian. Acad. Sci. Sect. A, 82, 121-129, 1975.

Rastogi, R. G. and Woodman R. F.: Spread F in equatorial ionograms associated with reversal of horizontal F-region electric field, Ann. Geophys., 34, 31-36, 1978.

Rastogi, R. G., Mullen, J. P. and Mckenzie, E.: Effect of magnetic activity on equatorial radio VHF scintillations and spread F, J. Gephys. Res., 86, 3661-3664, 1981.

Sizova, L. Z. and Zaitseva S. A.: The growth rate and decay of magnetospheric ring current. Moscow, Preprint IZMIRAN, 52 , 1-23, 1984.
Sizova, L. Z. and Pudovkin, M. I.: Disturbances of the daytime equatorial ionosphere associated with the $B_{z}$-component of interplanetary magnetic field, Geomagn. Aeron., 40, 246-249, 2000.

Sizova, L. Z.: The field-aligned currents effect on the equatorial geomagnetic field variations, Adv. Space. Res., 30, 2247-2252, 2002.

Zakharov, Y. Y., Nikitin, M. A., and Smirnov, O. A.: The response of low-latitude fields to the action of magnetospheric source, Geomagn. Aeron., 29, 381-388, 1989.

Zmuda, A. J. and Armstrong J. S.: The diurnal variation of the region of vector magnetic field changes associated with fieldaligned currents, J. Geophys. Res., 79, 2501-2502, 1974. 